\title{
Cardioprotective effect of adiponectin is partially mediated by its AMPK-independent antinitrative action.
}

\author{
Yajing Wang \\ Thomas Jefferson University \\ Ling Tao \\ Thomas Jefferson University \\ Yuexing Yuan \\ Thomas Jefferson University \\ Wayne Bond Lau \\ Thomas Jefferson University \\ Rond \\ Thomas Jefferson University \\ Part of the Emergency Medicine Commons

\section{Let us know how access to this document benefits you}

\section{Recommended Citation}

Wang, Yajing; Tao, Ling; Yuan, Yuexing; Lau, Wayne Bond; Li, Rong; Lopez, Bernard L.;

Christopher, Theodore A.; Tian, Rong; and Ma, Xin-Liang, "Cardioprotective effect of adiponectin is partially mediated by its AMPK-independent antinitrative action." (2009). Department of

Emergency Medicine Faculty Papers. Paper 158.

https://jdc.jefferson.edu/emfp/158

This Article is brought to you for free and open access by the Jefferson Digital Commons. The Jefferson Digital Commons is a service of Thomas Jefferson University's Center for Teaching and Learning (CTL). The Commons is a showcase for Jefferson books and journals, peer-reviewed scholarly publications, unique historical collections from the University archives, and teaching tools. The Jefferson Digital Commons allows researchers and interested readers anywhere in the world to learn about and keep up to date with Jefferson scholarship. This article has been accepted for inclusion in Department of Emergency Medicine Faculty Papers by an authorized administrator of the Jefferson Digital Commons. For more information, please contact: JeffersonDigitalCommons@jefferson.edu. 


\section{Authors}

Yajing Wang, Ling Tao, Yuexing Yuan, Wayne Bond Lau, Rong Li, Bernard L. Lopez, Theodore A. Christopher, Rong Tian, and Xin-Liang Ma 
1

2

3

4

5

6

7

8

9

10

11

12

13

14

15

16

17

18

19

20

21

22

23

24

25
Cardioprotective Effect of Adiponectin is Partially Mediated by its

AMPK-Independent Anti-Nitrative Action

Yajing Wang, $\mathrm{MD}, \mathrm{PhD}^{1 *}$, Ling Tao, $\mathrm{MD}, \mathrm{PhD}^{* \#}$, Yuexin Yuan, $\mathrm{PhD}^{1}$, Wayne Bond $\mathrm{Lau}, \mathrm{MD}^{1}$, Rong Li, MD, PhD, Bernard L. Lopez, MD${ }^{1}$, Theodore A. Christopher, MD', Rong Tian, $\mathrm{MD}, \mathrm{PhD}^{2}$, Xin-Liang $\mathrm{Ma}, \mathrm{MD}, \mathrm{PhD}^{1 \#}$

Running Title: Anti-apoptotic signaling of adiponectin

Address proofs to:

${ }^{\#}$ Xin L Ma, M.D., Ph.D.

Department of Emergency Medicine

1020 Sansom Street

Thompson Building, Room 239

Philadelphia, PA 19107

Tel: (215)955-4994

Fax: (215)923-6225

E-mail: Xin.Ma@Jefferson.edu

Or

${ }^{\#}$ Ling Tao, MD, PhD

Department of Emergency Medicine

1020 Sansom Street

Thompson Building, Room 239

Philadelphia, PA 19107

Tel: $\quad(215) 955-8897$

Fax: (215)923-6225

E-mail: Ling.Tao@Jefferson.edu

${ }^{1}$ Department of Emergency Medicine, Thomas Jefferson University, 1015 Walnut Street, Curtis Building, Room 220-222, Philadelphia, PA 19107

${ }^{2}$ Nuclear Magnetic Resonance Laboratory for Physiological Chemistry, Brigham and Women's Hospital, 221 Longwood Ave, Room 252, Boston, MA 02115 


\section{Abstract}

Adiponectin (APN) exerts its metabolic regulation largely through AMP-dependent protein kinase (AMPK). However, the role of AMPK in adiponectin's anti-apoptotic effect in ischemic/reperfused (I/R) adult cardiomyocytes remains incompletely understood. The current study was designed to determine the involvement of AMPK in the anti-apoptotic signaling of adiponectin. Cardiomyocytes from adult male mice overexpressing a dominant negative $\alpha_{2}$ subunit of AMPK (AMPK-DN) or wild-type (WT) littermates were subjected to simulated I/R (SI/R) and pretreated with $2 \mu \mathrm{g} / \mathrm{ml}$ gAPN or vehicle. SI/R-induced cardiomyocyte apoptosis was modestly increased in AMPK-DN cardiomyocytes $(\mathrm{P}<0.05)$. Treatment with gAPN significantly reduced SI/R-induced apoptosis in WT cardiomyocytes as well as in AMPK-DN cardiomyocytes, indicating that the anti-apoptotic effect of gAPN is partially AMPK-independent. Furthermore, gAPN-induced endothelial nitric oxide synthase (eNOS) phosphorylation was significantly reduced in AMPK-DN cardiomyocytes, suggesting the APN-eNOS signaling axis is impaired in AMPK-DN cardiomyocytes. Additional experiments demonstrated that treatment of AMPK-DN cardiomyocytes with gAPN reduced SI/R-induced NADPH oxidase overexpression, decreased superoxide generation, and blocked peroxynitrite formation to the same extent as that observed in WT cardiomyocytes. Collectively, our current study demonstrated that although the metabolic and eNOS activation effects of adiponectin is largely mediated by AMPK, the superoxide-suppressing effect of adiponectin is not mediated by AMPK, and this AMPK-independent anti-oxidant property of adiponectin increased nitric oxide bioavailability, and exerted significant anti-apoptotic effect.

Keywords: Apoptosis; Oxidative Stress; Nitric Oxide; Adipocytokine 
The incidence of obesity and type 2 diabetes mellitus is increasing worldwide, and both these conditions increase the risk of cardiovascular disease(22). Adiponectin is an adipocyte-produced protein that plays a critical role in glucose and lipid metabolism regulation(23). Prospective studies have demonstrated the association between decreased plasma adiponectin levels and increased cardiovascular morbidity in diabetic patients $(27 ; 34 ; 41)$ Clarification of the mechanisms by which adiponectin acts advantageously may contribute to our understanding of diabetic pathophysiology, and provide insight to a potential therapeutic modality.

AMP-activated protein kinase (AMPK) is a serine-threonine kinase that acts as an energy sensor in various cell types, and can be activated by hypoxic stress(33). When cellular energy is depleted, AMPK activity leads to downregulation of ATP-utilizing pathways and up-regulation of ATP-generating pathways to restore energy homeostasis $(8 ; 40)$. Considerable evidence exists that AMPK plays an essential role in adiponectin's metabolic regulatory, anti-inflammatory, and vasculoprotective actions(19). However, recently published studies utilizing AMPK inhibitors in determining the involvement of AMPK in adiponectin's cardioprotective action have yielded inconsistent results $(14 ; 28 ; 30)$. The role of AMPK in adiponectin's anti-ischemic and cardioprotective action remains incompletely understood.

The aims of the present study were 1) to determine whether exogenous adiponectin supplementation could attenuate myocardial apoptosis in cardiomyocytes subjected to simulated ischemia/reperfusion $(\mathrm{SI} / \mathrm{R}), 2)$ to determine whether adiponectin exerts its effects in an AMPK-dependent fashion, and 3) to dissect the 
molecular mechanisms underlying adiponectin's cardioprotective role.

\section{$\underline{\text { Methods }}$}

Adult mouse cardiomyocyte culture: All experiments were performed on adult (8 to 10 weeks) male mice overexpressing a dominant negative $\alpha_{2}$ subunit (D157A) of AMPK (AMPK-DN) or male littermate controls expressing the wild type of $\alpha_{2}$ subunit of AMPK (WT). Generation, breeding, phenotype characteristics, and genotyping of these mice have previously been described in detail(37). Experiments were performed in adherence with the National Institutes of Health Guidelines on the use of Laboratory Animals, and were approved by the Thomas Jefferson University Committee on Animal Care. Mice were anesthetized with 2\% isoflurane, and hearts were removed and perfused at $37^{\circ} \mathrm{C}$ for $\sim 3$ min with a $\mathrm{Ca}^{2+}$-free bicarbonate-based buffer. Enzymatic digestion was initiated by adding collagenase type B/D to the perfusion solution. When the hearts became swollen and hard after $\sim 3$ min of digestion, $50 \mu \mathrm{M} \mathrm{Ca}^{2+}$ was added to the enzyme solution. Approximately 7 min later, the left ventricle was removed, cut into several sections, and further digested in a shaker for $10 \mathrm{~min}$ at $37^{\circ} \mathrm{C}$ in the same enzyme solution. The supernatant containing the dispersed myocytes was filtered into a sterilized tube and centrifuged at $800 \mathrm{x} \mathrm{g}$ for $1 \mathrm{~min}$. The cell pellet was then resuspended in bicarbonate-based buffer containing $125 \mu \mathrm{M} \mathrm{Ca}^{2+}$. After the myocytes were pelleted by gravity for $\sim 10 \mathrm{~min}$, the supernatant was aspirated and the myocytes were resuspended in bicarbonate-based buffer containing $250 \mu \mathrm{M} \mathrm{Ca}^{2+}$. Myocytes were plated at $0.5-1 \times 10^{4}$ cells. $\mathrm{cm}^{-2}$ in the 
culture dishes precoated with mouse laminin.

After $1 \mathrm{~h}$ of culture in a $5 \% \mathrm{CO}_{2}$ incubator at $37^{\circ} \mathrm{C}$, cardiomyocytes were subjected to simulated ischemia/reperfusion ( $\mathrm{SI} / \mathrm{R})$ as originally described by Isner and colleagues(21) and modified in our recently published study(11). In brief, glucose-free culture medium was first gassed for 5 minutes with a hypoxic gas mixture $\left(95 \% \mathrm{~N}_{2} / 5 \% \mathrm{CO}_{2}\right)$. Normal culture medium was quickly replaced with the hypoxia-hypoglycemic medium containing either vehicle or globular domain of adiponectin (gAPN, $2 \mu \mathrm{g} / \mathrm{ml}$ ), and cardiomyocytes were placed in a Napco $8000 \mathrm{WJ}$ hypoxia $\left(1 \% \mathrm{O}_{2} / 5 \% \mathrm{CO}_{2} / 94 \% \mathrm{~N}_{2}\right)$ incubator (Thermo Scientific, Waltham, MA). The concentration of gAPN was selected based on our previous publication(32). After 3 hours of hypoxia-hypoglycemic culture, the hypoxia/hypoglycemic medium was replaced with normal culture medium (containing same concentration of vehicle or gAPN). Cells were then incubated under normoxic conditions in a $\mathrm{CO}_{2}$ incubator for an additional 6 hours.

Assessment of cardiomyocyte apoptosis: Cardiomyocyte apoptosis was determined by DNA ladder formation, terminal deoxynucleotidyl transferase-mediated dUTP nick-end labeling (TUNEL) staining, and caspase 3 activity as reported in our previous study(32). For DNA fragmentation assay, total DNA was isolated with the Gentra Puregene Tissue DNA Isolation Kit (QIAgen, Valencia, CA) per manufacturer's instructions. $10 \mu \mathrm{g}$ of DNA was loaded into $1.8 \%$ agarose gel containing $0.5 \mu \mathrm{g} \mathrm{ml}^{-1}$ ethidium bromide. DNA electrophoresis was carried out at 60 V for 1 to 2 hours. DNA ladder formation, a "hallmark" of tissue apoptosis, was 
visualized under ultraviolet light and photographed for permanent record. TUNEL assay was performed utilizing the In Situ Cell Death Detection Kit (Roche, Palo Alto, CA). Briefly, cells were fixed with $10 \%$ paraformaldehyde, and incubated with the TUNEL reaction mixture containing TdT-mediated dUTP nick end labeling. Nuclei were counter-stained with 4,6-diamidino-2-phenylindole (DAPI). Samples were visualized on an Olympus BX51 Fluorescence Microscope, and digital images were acquired with IP Lab Imagine Analysis Software (Version 3.5, Scanalytics, Fairfax, VA, USA). The index of apoptosis (number of TUNEL positively stained nuclei/total number of nuclei $\mathrm{x} 100 \%$ ) was automatically calculated and exported for further analysis. Assays were performed in a blinded manner. For caspase-3 activity assay, cells were lysed and total protein concentration was determined by the bicinchoninic acid (BCA) method. To each well of a 96-well plate, supernatant containing $200 \mu \mathrm{g}$ of protein was loaded and incubated with $25 \mu \mathrm{g}$ Ac-DEVD-pNA at $37^{\circ} \mathrm{C}$ for 1.5 hours. pNA was cleaved from DEVD by activated caspase-3, and the free pNA was quantified using a SpectraMax-Plus microplate spectrophotometer (Molecular Devices, Sunnyvale, CA) at $405 \mathrm{~nm}$. Caspase-3 activity was expressed as nmol $\mathrm{pNA} / \mathrm{h} / \mathrm{mg}$ protein.

Quantification of superoxide production: Superoxide production in viable cardiomyocytes was measured by lucigenin-enhanced chemiluminescence as described previously(8), and expressed as relative light units (RLU) per second per milligram protein (RLU/s/mg protein).

Western blot analysis: The post-treatment cultured cardiomyocytes were collected 
in lysis buffer. Protein was separated on SDS-PAGE gels, transferred to

150 nitrocellulose membranes, and detected with antibodies against eNOS, peNOS

151 (Upstate, Chicago, IL), acetyl-CoA carboxylase (ACC), pACC, and gp91 ${ }^{\text {phox }}$ (BD

152 Bioscience Laboratories, San Jose, CA). Nitrocellulose membranes were then

153 incubated with HRP-conjugated anti-rabbit immunoglobulin G antibody (Cell

154 Signaling, Danvers, MA) for $1 \mathrm{~h}$. The blot was developed with a Supersignal

155 Chemiluminescence Detection Kit (Pierce, Rockford, IL). The band was visualized

156 with a Kodak Image Station 400 (Rochester, NY), and the band densities were

157 analyzed with Kodak 1-Dimensional software.

Immunocytochemistry: At the end of experiments, cardiomyocytes were fixed with formaldehyde (4\% in PBS) and stained with an anti-nitrotyrosine antibody (Upstate, Chicago, IL). Immunostaining was developed with a Vectastain ABC kit (Vector Laboratories, Burlingame, CA), and visualized with an Olympus BX51 Fluorescence Microscope.

Quantification of tissue nitrotyrosine content: Cardiomyocyte nitrotyrosine content, the footprint of peroxynitrite $\left(\mathrm{ONOO}^{-}\right)$formation and an index of nitric oxide (NO) inactivation by superoxide, was determined using a nitrotyrosine ELISA kit (Cell Sciences, Canton, MA) per manufacturer's instructions.

Statistical Analysis: All values in the text and figures are presented as means \pm SEM of $n$ independent experiments. All data (except Western blot density) were subjected to ANOVA followed by Bonferroni correction for post-hoc $t$ test. Western blot 
densities were analyzed with the Kruskal-Wallis test followed by Dunn's post-hoc test. Probabilities of 0.05 or less were considered to be statistically significant.

\section{$\underline{\text { Results }}$}

$\underline{\text { SI/R-induced apoptosis was increased in cardiomyocytes isolated from AMPK-DN }}$ mice and gAPN's anti-apoptotic effects were largely retained in AMPK-DN cardiomyocytes: Adult cardiomyocytes are terminally differentiated, and spontaneous apoptosis occurs even under normal culture conditions. In our system, approximately $14 \%$ cardiomyocytes were TUNEL positive after 9 hours of culture with normal oxygen and glucose (Figure 1, Sham SI/R). In cardiomyocytes isolated from WT littermates, 3 hours of SI followed by 6 hours of reperfusion markedly stimulated apoptotic cell death, as evidenced by a 2.4 -fold increase in TUNEL staining over time-matched control (Figure 1), clear DNA ladder formation (Figure $2 \mathrm{~A}$ ), and a 2.3-fold increase in caspase 3 activity (Figure 2B). Consistent with our previous in vivo experimental results(32), treatment with gAPN significantly reduced SI/R-induced apoptosis (Figure 1 and 2, $\mathrm{P}<0.01$ ). Cardiomyocytes isolated from AMPK-DN mice were morphologically normal, and exhibited spontaneous apoptosis in normal culture conditions to an extent comparable to cardiomyocytes isolated from WT mice (Figures 1 and 2B). However, when subjected to SI/R, AMPK-DN cardiomyocytes exhibited modestly greater TUNEL positive staining and caspase 3 activity than WT cardiomyocytes (TUNEL: $38.4 \pm 0.97 \%$ vs. $33.2 \pm 2.2 \%, \mathrm{P}<0.05$; caspase 3: $6.2 \pm 0.35$ vs. $5.3 \pm 0.12 \mathrm{nmol} \mathrm{pNA} / \mathrm{h} / \mathrm{mg}$ protein, $\mathrm{P}<0.05)$. These results indicate that the susceptibility to ischemia/reperfusion stress was significantly 
increased in the presence of impaired AMPK signaling. Most interestingly, the anti-apoptotic property of gAPN was reduced but not lost in AMPK-DN cardiomyocytes. Specifically, treatment of AMPK-DN cardiomyocytes with gAPN significantly reduced TUNEL staining $(29.5 \pm 1.5 \%$ vs. $38.4 \pm 0.97 \%, \mathrm{P}<0.01$, Figure 1$)$, partially blocked DNA ladder formation (Figure 2A), and significantly decreased caspase 3 activity ( $4.1 \pm 0.52$ vs. $6.2 \pm 0.35 \mathrm{nmol} \mathrm{pNA} / \mathrm{h} / \mathrm{mg}$ protein, $\mathrm{P}<0.01$, Figure $2 \mathrm{~B}$ ). To obtain more evidence in supporting our conclusion that gAPN protects cardiomyocyte partially through AMPK-independent pathway, an additional experiment was performed. Adult cardiomyocytes were isolated from AMPK-DN mice as described above. Compound $\mathrm{C}$, a selective APMK inhibitor, was added 30 minutes before APN treatment $(20 \mu \mathrm{mo} / \mathrm{L})(31)$, and AMPK activity was determined by SAMS peptide $/\left(\gamma^{-32} \mathrm{P}\right)$ ATP assay(31). Although AMPK activity was nearly completely inhibited after this combinational treatment $(4.4 \pm 1.1 \%$ of control), the cardioprotective effects of gAPN remained to be significant (TUNEL staining: $30.4 \pm 1.2 \%$ vs. $40.3 \pm 2.1$ in vehicle group, $\mathrm{P}<0.01$; Caspase- 3 activity: $4.4 \pm 0.32$ vs $6.7 \pm 0.45 \mathrm{nmol} \mathrm{pNA} / \mathrm{h} / \mathrm{mg}$ protein, $\mathrm{P}<0.01)$. These results demonstrated that gAPN protects cardiomyocytes from SI/R injury partially in an AMPK-independent fashion. Adiponectin-induced activation of ACC, a primary downstream molecule of AMPK, was lost in AMPK-DN cardiomyocytes: The observation that the anti-apoptotic effect of gAPN was largely retained in AMPK-DN cardiomyocytes is somewhat surprising, because this is opposite of previously published results demonstrating the abolishment of metabolic regulatory and vascular protective effects of adiponectin when AMPK is 
214 pharmacologically or genetically inhibited $(4 ; 38)$. One possible explanation for this

215 discrepancy is that our AMPK-DN approach failed to effectively block

216 adiponectin-induced AMPK activation. To directly address this issue, Acetyl-CoA

217 carboxylase (ACC) phosphorylation, a major signaling step through which AMPK

218 exerts its metabolic regulation, was determined. As summarized in Figure 3A,

219 treatment with gAPN significantly increased ACC phosphorylation in cardiomyocytes

220 isolated from WT (left panel), but not from AMPK-DN heart (right panel). Moreover,

221 a 1.8-fold increase in ACC phosphorylation was observed in WT cardiomyocytes

222 following SI/R, and treatment with gAPN further enhanced (1.2-fold over SI/R +

223 vehicle, $\mathrm{P}<0.05$ ) ACC phosphorylation modestly (Figure 3B). However, SI/R-induced

224 ACC phosphorylation was lost in AMPK-DN cardiomyocytes. More importantly,

225 treatment with gAPN failed to stimulate ACC phosphorylation in these cells (Figure

$2263 \mathrm{~B}$, right panel). These results demonstrated that the AMPK signaling system was

227 indeed blocked in our AMPK-DN cardiomyocytes.

228 Adiponectin-induced eNOS phosphorylation was significantly reduced in AMPK-DN

229 cardiomyocytes: Substantial evidence exists that the physiological or pharmacological

230 concentration of NO produced by eNOS or NO donors is cardioprotective. Moreover,

231 previous studies have demonstrated that adiponectin possesses strong eNOS

232 phosphorylation ability, and stimulates NO production in cultured endothelial cells.

233 We thus explored the possibility that gAPN may cause eNOS phosphorylation in

234 cardiomyocytes independent of AMPK, and thus reduce cardiomyocyte apoptosis in

235 AMPK-DN cardiomyocytes. As summarized in Figure 4, treatment of WT 
cardiomyocytes subjected to sham SI/R (4A) or SI/R (4B) with gAPN resulted in significant eNOS phosphorylation. However, gAPN-induced eNOS phosphorylation was significantly blunted, although not completely lost, in AMPK-DN cardiomyocytes. These results indicate that adiponectin induces cardiomyocyte eNOS phosphorylation predominantly by the AMPK-mediated pathway, and a relatively weaker AMPK-independent eNOS phosphorylation pathway exists in this cell type.

Adiponectin reduced superoxide production and attenuated gp91 ${ }^{\text {phox }}$ expression in largely AMPK-independent fashion: Data presented in Figures 1 and 2 indicated that greater than $70 \%$ of the anti-apoptotic effect of gAPN was retained in cardiomyocytes isolated from AMPK-DN heart. In contrast, greater than $70 \%$ of eNOS activation effect, and greater than $95 \%$ of ACC activation effect of gAPN were blocked in AMPK-DN cardiomyocytes. These results strongly suggest that mechanisms other than the metabolic benefit and eNOS activation are active and responsible for the anti-apoptotic effect of gAPN in AMPK-DN cardiomyocytes. It is well-recognized that overproduction of reactive oxygen species plays a critical pathogenic role in myocardial ischemia/reperfusion injury. We next determined the effect of gAPN on SI/R-induced superoxide overproduction, and the involvement of AMPK in this action. As summarized in Figure 5, when compared to WT cardiomyocytes, AMPK-DN cardiomyocytes exhibited slightly increased (not statistically significant) basal superoxide production, with significantly increased SI/R-induced superoxide overproduction $(\mathrm{P}<0.05)$. Most interestingly, treatment with gAPN markedly reduced superoxide overproduction in WT as well as AMPK-DN cardiomyocytes (Figure 5). 
Previous studies from other investigators and our laboratory have demonstrated

that NADPH oxidase is a major cytosolic source of ischemia/reperfusion-induced superoxide overproduction in the heart. Having demonstrated that gAPN inhibits superoxide overproduction largely in an AMPK-independent fashion, we next determined its effect on SI/R-induced upregulation of gp91 ${ }^{\text {phox }}$, the membrane component of NADPH oxidase. Compared to WT, mRNA and protein expression of gp9 $1^{\text {phox }}$ were slightly increased in AMPK-DN cardiomyocytes before SI/R $(\mathrm{P}>0.05)$. However, SI/R-induced gp91 ${ }^{\text {phox }}$ mRNA (2.69 \pm 0.14 -fold over basal expression in AMPK-DN cardiomyocytes vs. 2.11 \pm 0.15 -fold over basal expression in WT cardiomyocytes, $\mathrm{P}<0.05$ ) and protein overexpression (Figure $5 \mathrm{~B}$, second bar vs. fifth bar, $\mathrm{P}<0.05$ ) were significantly increased in AMPK-DN cardiomyocytes. Most interestingly, treatment of AMPK-DN cardiomyocytes with gAPN inhibited SI/R-induced $\quad$ gp9 $1^{\text {phox }}$ mRNA $\quad(79.1 \pm 3.8 \%$ and $77.9 \pm 3.1 \%$ reduction from vehicle-treated group in AMPK-DN and WT cardiomyocytes, respectively) and protein overexpression (Figure 5B) to a comparable level seen in WT cardiomyocytes. Collectively, these results demonstrate that gAPN inhibited NADPH oxidase overexpression and subsequent superoxide overproduction in an AMPK-independent fashion.

Inducible nitric oxide synthase (iNOS) is responsible for peroxynitrite overproduction in cardiomyocytes subjected to SI/R: Inactivation of nitric oxide with subsequent formation of peroxynitrite is the most pathologically relevant mechanism through which superoxide exerts its cytotoxic effects. Superoxide reacts with NO in 1:1 ratio 
and peroxynitrite is maximally produced when both superoxide and NO production are simultaneously elevated. Although eNOS and nNOS are expressed in cardiomyocytes, basal NO production from these forms of NOS is very low. Moreover, eNOS phosphorylation is reduced in AMPK-DN cardiomyocytes whereas

peroxynitrite is increased in these cells, indicating that eNOS is not responsible for peroxynitrite formation in AMPK-DN cardiomyocytes. We thus determined iNOS expression in $\mathrm{SI} / \mathrm{R}$ cardiomyocytes, and elucidated its role in SI/R-induced peroxynitrite production. As illustrated in Figure 6, no significant iNOS expression was detected in cardiomyocytes isolated from either WT or AMPK-DN hearts, if not subjected to SI/R. However, SI/R caused significant iNOS expression, which was markedly inhibited by gAPN in WT or AMPK-DN cardiomyocytes (Figure 6A). In addition, treatment with $1400 \mathrm{~W}(20 \mu \mathrm{g} / \mathrm{ml})$, a selective iNOS inhibitor, at the time of reperfusion significantly inhibited peroxynitrite formation in ischemia/reperfused cardiomyocytes (Figure 6B). These results demonstrated that NO generated from iNOS is responsible for SI/R-induced peroxynitrite formation, which was inhibited by gAPN in an AMPK-independent fashion.

Diphenyleneiodonium (DPI), an NADPH oxidase inhibitor, significantly reduced peroxynitrite formation and attenuated caspase 3 activation after SI/R: Results presented above strongly suggest that gAPN attenuates post-ischemic cardiomyocyte apoptosis by inhibiting NADPH oxidase-derived superoxide production and subsequent peroxynitrite formation. To obtain more evidence supporting this conclusion, additional experiments were performed. As summarized in Figure 7, 
treatment with DPI, a selective NADPH oxidase inhibitor, reduced peroxynitrite formation (7A) and cardiomyocytes apoptosis (7B) to a comparable level seen with gAPN treatment. Moreover, no additive effect in either peroxynitrite inhibition or caspase-3 suppression was observed when SI/R cardiomyocytes were treated with gAPN plus DPI. These new results further support a conclusion that inhibiting NADPH oxidase-derived superoxide overproduction is largely responsible for gAPN's anti-oxidant/anti-nitrative effects.

\section{$\underline{\text { Discussion }}$}

In a recent in vivo animal study, we have demonstrated that AMPK deficiency enhanced myocardial ischemia/reperfusion injury but has minimal effect on adiponectin's anti-oxidant/anti-nitrative protection(36). Our current study not only confirmed our previous finding in a different experimental model, but more importantly, provided new evidence demonstrating that iNOS/NADPH oxidase overexpression is sufficient to increase nitrative/oxidative stress and that gAPN exerts its AMPK-independent cardioprotetcion partially through iNOS/NADPH oxidase suppression.

Adiponectin, also known as Acrp30, is an adipocytokine originally thought to be exclusively secreted from adipose tissue( $2 ; 5)$. However, growing evidence indicates that adiponectin is synthesized and secreted by adult human and murine cardiomyocytes $(7 ; 15 ; 26)$, although its physiological and pathologic significance remains completely unknown. In human and mouse plasma, adiponectin exists in three major oligomeric forms: trimers, hexamers, and a high-molecular weight 
form(25). A proteolytic cleavage product of adiponectin that includes its globular domain, known as globular adiponectin or gAPN, may occur in human and mouse plasma(10; 39). Recently, it has been shown that the cleavage of adiponectin by leukocyte elastase secreted from activated monocytes and/or neutrophils could be responsible for the generation of gAPN(35). However, the physiological or pathophysiological role of this proteolytic cleavage product remains largely unknown, and its relationship to cardiovascular disease is unclear(13).

After approximately 10 years of extensive experimental and clinical investigation, it is now clear that adiponectin has 3 major biologic functions, including an insulin sensitization/metabolic regulatory function (in the liver and muscle), an anti-inflammatory/vascular protective function, and an anti-ischemic/cardioprotective function(12). Substantial accumulated evidence supports the concept that AMPK plays an essential role in adiponectin's metabolic regulatory and vascular protective actions. Specifically, pharmacological inhibition of AMPK activity or genetic inhibition of AMPK expression virtually abolishes the metabolic(3; 38), anti-inflammatory(17), and vasculoprotective $(24 ; 29)$ effects of adiponectin. However, although the evidence for the anti-ischemic/cardioprotective effects of adiponectin is strong, whether AMPK is the central mediator of this effect remains uncertain.(9)

Two ex vivo studies reported that AMPK is essential for the cardioprotective effects of full length adiponectin (fAPN). The study by Shinmura(30) et al demonstrated that short-term caloric restriction protected the heart by increasing serum total adiponectin levels with subsequent AMPK activation. In a more recent 
study, Gonon et al reported that full length adiponectin protected against myocardial ischemia-reperfusion injury via the AMPK/Akt/NO signaling axis(14). However, although the data clearly demonstrated that administration of fAPN in isolated perfused hearts resulted in AMPK phosphorylation, it was not determined whether the protective effects of adiponectin were blocked when AMPK was inhibited, and no cause-effect relationship was established. It thus remains unclear whether AMPK phosphorylation is a necessary step for adiponectin to exert anti-ischemic/cardioprotective effects. In the first study reporting adiponectin's cardioprotective effect, Shibata et al(28) demonstrated the varying importance of AMPK in fAPN's cardioprotective effect in different models. Specifically, fAPN blocks hypoxia/reoxygenation-induced neonatal cardiomyocyte apoptosis largely through AMPK activation. In contrast, its inhibitory effect on LPS-induced TNF $\alpha$ production is completely AMPK-independent. Moreover, in vivo administration of NS398, a COX-2 inhibitor, partially blocked the infarct-sparing action of exogenous fAPN, suggesting that COX-2 plays a significant role in fAPN's cardioprotection after ischemia/reperfusion. These seemingly conflicting results underscore the complexity of adiponectin signaling, and suggest that multiple signaling mechanisms are involved in adiponectin's cardioprotection in adult animals.

AMPK is activated in response to many types of cellular stress, particularly to elevated ratios of AMP to ATP, which occurs during myocardial ischemia(16). Indeed, our current experimental results (Figure 3) demonstrated that ACC phosphorylation, an index for AMPK activity, was markedly increased when cardiomyocytes were 
subjected to SI/R. However, treatment with gAPN under this particular pathologic condition only elicited moderate additional AMPK activation. These results strongly suggest that the degree of AMPK involvement in adiponectin's biological functions is determined by the intracellular environment, particularly AMP concentration. Under those pathologic conditions where intracellular AMP concentrations are not elevated (i.e., muscular insulin resistance and vascular inflammation), AMPK might be the most important molecule in adiponectin intracellular signaling, as previously reported. In contrast, under those pathologic conditions where intracellular AMP concentrations are elevated, and AMPK has already been significantly activated (such as myocardial ischemia), adiponectin may exert its biological actions largely through signaling molecules other than AMPK.

Numerous studies have demonstrated that nitric oxide at physiologic or pharmacologic concentrations is anti-apoptotic and cardioprotective(18). Moreover, molecules capable of stimulating eNOS phosphorylation (e.g., insulin) reduce apoptotic cell death in the ischemic/reperfused heart, attenuating myocardial reperfusion injury(11). As first reported by Chen et al(6), and subsequently confirmed by other investigators(20), adiponectin stimulates eNOS phosphorylation and increases NO production in cultured endothelial cells. However, the AMPK-independent anti-apoptotic action of gAPN as observed in the current study cannot be attributed entirely to gAPN's eNOS stimulatory and NO productive effects, because $>70 \%$ eNOS phosphorylation by gAPN was lost in AMPK-DN cardiomyocytes. In contrast, our current study provided clear evidence that 
SI/R-induced NADPH oxidase upregulation and superoxide overproduction are inhibited by gAPN in an AMPK-independent fashion. Although the precise signaling mechanisms by which gAPN may inhibit NADPH oxidase expression cannot be addressed in the current study, the AMPK-independent anti-oxidant effect of gAPN suggests a likely mechanism responsible for gAPN's anti-apoptotic and cardioprotective effects in AMPK-DN cardiomyocytes.

The downregulation of NADPH oxidase expression and suppression of superoxide production by gAPN can provide cardioprotection by multiple mechanisms. First, reduction in superoxide production in ischemic/reperfused cardiomyocytes will reduce the production of the hydroxyl radical, thus attenuating oxidative cell injury. Second, superoxide inactivates nitric oxide in a nearly diffusion-limited rate reaction(1). By reducing superoxide production, gAPN increases bioactive NO concentration, thus preserving the anti-apoptotic and cytoprotective function of NO. Finally, by reducing the superoxide/NO reaction, gAPN blocks the formation of peroxynitrite, a highly cytotoxic species that causes cell death by multiple mechanisms, thus attenuating peroxynitrite-induced cell death.

It should be indicated that the globular domain of adiponectin was investigated in the current study. Whether the AMPK-independent anti-apoptotic effect and responsible signaling mechanisms identified in this study are unique to this particular isoform of adiponectin, or are shared by other adiponectin isoforms, remains unknown. Additional experiments addressing this question are currently under investigation. 
1. Beckman JS and Koppenol WH. Nitric oxide, superoxide, and peroxynitrite: The good, the bad, and the ugly. Am J Physiol Cell Physiol 271: C1424-C1437, 1996.

4. Bruce CR, Mertz VA, Heigenhauser GJ and Dyck DJ. The stimulatory effect of globular adiponectin on insulin-stimulated glucose uptake and fatty acid oxidation is impaired in skeletal muscle from obese subjects. Diabetes 54: 3154-3160, 2005.

5. Chandran M, Phillips SA, Ciaraldi T and Henry RR. Adiponectin: more than just another fat cell hormone? Diabetes Care 26: 2442-2450, 2003.

6. Chen H, Montagnani M, Funahashi T, Shimomura I and Quon MJ. Adiponectin stimulates production of nitric oxide in vascular endothelial cells. J Biol Chem 278: 45021-45026, 2003.

\section{Ding G, Qin Q, He N, Francis-David SC, Hou J, Liu J, Ricks E and Yang Q. Adiponectin} and its receptors are expressed in adult ventricular cardiomyocytes and upregulated by activation of peroxisome proliferator-activated receptor gamma. J Mol Cell Cardiol 43: 73-84, 2007.

8. Dolinsky VW and Dyck JR. Role of AMP-activated protein kinase in healthy and diseased 
9. Dyck JRB. The Ischemic Heart: Starving to Stimulate the Adiponectin-AMPK Signaling Axis. Circulation 116: 2779-2781, 2007. 
16. Hardie DG. Minireview: The AMP-Activated Protein Kinase Cascade: The Key Sensor of Cellular Energy Status. Endocrinology 144: 5179-5183, 2003.

17. Hattori Y, Nakano Y, Hattori S, Tomizawa A, Inukai K and Kasai K. High molecular

18. Heusch G, Boengler K and Schulz R. Cardioprotection: Nitric Oxide, Protein Kinases, and Mitochondria. Circulation 118: 1915-1919, 2008.

19. Kadowaki T and Yamauchi T. Adiponectin and Adiponectin Receptors. Endocr Rev 26: 439-451, 2005.

20. Motoshima H, Wu X, Mahadev K and Goldstein BJ. Adiponectin suppresses proliferation and superoxide generation and enhances eNOS activity in endothelial cells treated with oxidized LDL. Biochem Biophys Res Commun 315: 264-271, 2004.

21. Namiki A, Brogi E, Kearney M, Kim EA, Wu T, Couffinhal T, Varticovski L and Isner JM. Hypoxia induces vascular endothelial growth factor in cultured human endothelial cells. J Biol Chem 270: 31189-31195, 1995.

22. Norhammar A, Lindback J, Ryden L, Wallentin $L$ and Stenestrand U. Improved but still high short- and long-term mortality rates after myocardial infarction in patients with diabetes mellitus: a time-trend report from the Swedish Register of Information and Knowledge about 
23. Ouchi N, Kihara S, Funahashi T, Matsuzawa $\mathbf{Y}$ and Walsh K. Obesity, adiponectin and vascular inflammatory disease. Curr Opin Lipidol 14: 561-566, 2003.

24. Ouchi N, Kobayashi H, Kihara S, Kumada M, Sato K, Inoue T, Funahashi T and Walsh K. kinase and Akt signaling in endothelial cells. J Biol Chem 279: 1304-1309, 2004. 
Angiogenesis in Response to Tissue Ischemia through Stimulation of AMP-activated Protein Kinase Signaling. J Biol Chem 279: 28670-28674, 2004.

30. Shinmura K, Tamaki K, Saito K, Nakano Y, Tobe T and Bolli R. Cardioprotective Effects of Short-Term Caloric Restriction Are Mediated by Adiponectin via Activation of AMP-Activated Protein Kinase. Circulation 116: 2809-2817, 2007.

31. Sun W, Lee TS, Zhu M, Gu C, Wang Y, Zhu Y and Shyy JYJ. Statins Activate AMP-Activated Protein Kinase In Vitro and In Vivo. Circulation 114: 2655-2662, 2006.

32. Tao L, Gao E, Jiao X, Yuan Y, Li S, Christopher TA, Lopez BL, Koch W, Chan L, Goldstein BJ and Ma XL. Adiponectin cardioprotection after myocardial ischemia/reperfusion involves the reduction of oxidative/nitrative stress. Circulation 115: 1408-1416, 2007.

33. Tian R and Balschi JA. Interaction of insulin and AMPK in the ischemic heart: another chapter in the book of metabolic therapy? Circ Res 99: 3-5, 2006.

34. Tschritter O, Fritsche A, Thamer C, Haap M, Shirkavand F, Rahe S, Staiger H, Maerker E, Haring $\mathbf{H}$ and Stumvoll M. Plasma adiponectin concentrations predict insulin sensitivity of both glucose and lipid metabolism. Diabetes 52: 239-243, 2003.

35. Waki H, Yamauchi T, Kamon J, Kita S, Ito Y, Hada Y, Uchida S, Tsuchida A, Takekawa S and Kadowaki T. Generation of globular fragment of adiponectin by leukocyte elastase secreted by monocytic cell line THP-1. Endocrinology 146: 790-796, 2005. 
R, Koch W and Ma XL. AMP-activated protein kinase deficiency enhances myocardial ischemia/reperfusion injury but has minimal effect on the antioxidant/antinitrative protection of adiponectin. Circulation 119: 835-844, 2009.

37. Xing Y, Musi N, Fujii N, Zou L, Luptak I, Hirshman MF, Goodyear LJ and Tian R. Glucose Metabolism and Energy Homeostasis in Mouse Hearts Overexpressing Dominant Negative \{alpha\}2 Subunit of AMP-activated Protein Kinase. J Biol Chem 278: 28372-28377, 2003.

38. Yamauchi T, Kamon J, Minokoshi Y, Ito Y, Waki H, Uchida S, Yamashita S, Noda M, Kita S, Ueki K, Eto K, Akanuma Y, Froguel P, Foufelle F, Ferre P, Carling D, Kimura S, Nagai R, Kahn BB and Kadowaki T. Adiponectin stimulates glucose utilization and fatty-acid oxidation by activating AMP-activated protein kinase. Nat Med 8: 1288-1295, 2002.

39. Yamauchi T, Kamon J, Waki H, Terauchi Y, Kubota N, Hara K, Mori Y, Ide T, Murakami K, Tsuboyama-Kasaoka N, Ezaki O, Akanuma Y, Gavrilova O, Vinson C, Reitman ML, Kagechika H, Shudo K, Yoda M, Nakano Y, Tobe K, Nagai R, Kimura S, Tomita M, Froguel P and Kadowaki T. The fat-derived hormone adiponectin reverses insulin resistance associated with both lipoatrophy and obesity. Nat Med 7: 941-946, 2001.

40. Young LH. AMP-Activated Protein Kinase Conducts the Ischemic Stress Response Orchestra. Circulation 117: 832-840, 2008.

41. Zietz B, Herfarth H, Paul G, Ehling A, Muller-Ladner U, Scholmerich J and Schaffler A. Adiponectin represents an independent cardiovascular risk factor predicting serum 
534 This research was supported by the following grants: NIH 2R01HL-63828, American

535 Diabetes Association Research Award 7-08-RA-98, American Heart Association 536 Grant-in-Aid 0855554D, Commonwealth of Pennsylvania-Department of Health (to

537 X.L.M.), American Diabetes Association 7-06-JF59 (to L.T.), and Emergency 538 Medicine Foundation Career Development Grant (to W.L.). 


\section{Figure Legend}

Figure 1. Effect of gAPN on SI/R-induced apoptosis in cardiomyocytes isolated from wild type mice (Left panel, WT) and AMPK-DN mice (right panel). A: Representative photomicrographs of TUNEL staining from cardiomyocytes subjected to sham $\mathrm{SI} / \mathrm{R}$ or $3 \mathrm{~h}$ SI followed by $6 \mathrm{~h} \mathrm{R}$ treated with vehicle or gAPN (green: TUNEL-positive nuclei; blue: total nuclei). B: Quantification summary of apoptotic index calculated as TUNEL positive/total $\mathrm{x} 100 \%$. ${ }^{*} \mathrm{P}<0.05$, ${ }^{*} * \mathrm{P}<0.01$ vs. sham $\mathrm{SI} / \mathrm{R}$; ${ }^{\# \#} \mathrm{P}<0.01$ vs. SI/R+V. $\mathrm{N}=14-16$ wells/group with cardiomyocytes isolated from 6 to 8 mice. Assays were performed at the end of 6 hours of reperfusion or sham reperfusion.

Figure 2. Effect of gAPN on SI/R-induced DNA fragmentation (A) and caspase 3 activation (B). ${ }^{*} \mathrm{P}<0.05,{ }^{*} \mathrm{P}<0.01$ vs. sham $\mathrm{SI} / \mathrm{R} ;{ }^{\# \#} \mathrm{P}<0.01$ vs. $\mathrm{SI} / \mathrm{R}+\mathrm{V} . \mathrm{N}=4-6$ wells/group for DNA fragmentation; $\mathrm{N}=14-16$ wells/group for caspase 3 activity assay. Cells are isolated from 6 to 8 mice. Assays were performed at the end of 6 hours of reperfusion or sham reperfusion.

Figure 3. Effect of gAPN on ACC phosphorylation in cardiomyocytes isolated from WT (left panel) and AMPK-DN mice (right panel) with (B) or without (A) SI/R. ${ }^{* *} \mathrm{P}<0.01$ vs. vehicle $(\mathrm{A})$ or sham SI/R (B); ${ }^{\#} \mathrm{P}<0.05$ vs. SI/R+V. N=8-10 wells/group with cardiomyocytes isolated from 4 to 6 mice. Assays were performed 3 hours after reperfusion or sham reperfusion.

Figure 4. Effect of gAPN on eNOS phosphorylation in cardiomyocytes isolated from WT (left panel) and AMPK-DN mice (right panel) with (B) or without (A) SI/R. ${ }^{*} \mathrm{P}<0.05,{ }^{* *} \mathrm{P}<0.01$ vs. vehicle (A) or sham $\mathrm{SI} / \mathrm{R}(\mathrm{B}) ;{ }^{*} \mathrm{P}<0.05,{ }^{\# \#} \mathrm{P}<0.01$ vs. $\mathrm{SI} / \mathrm{R}+\mathrm{V}$. $\mathrm{N}=8-10$ wells/group with cardiomyocytes isolated from 4 to 6 mice. Assays were performed 3 hours after reperfusion or sham reperfusion

Figure 5. Effect of gAPN on SI/R-induced superoxide production determined with lucigenin-enhanced chemiluminescence (A) and gp91 ${ }^{\text {phox }}$ overexpression (B) in cardiomyocytes isolated from WT (left panel) and AMPK-DN mice (right panel). ${ }^{*} \mathrm{P}<0.05, \quad{ }^{* *} \mathrm{P}<0.01 \quad$ vs. sham $\mathrm{SI} / \mathrm{R} ; \quad{ }^{\#} \mathrm{P}<0.05,{ }^{\#} \mathrm{P}<0.01 \quad$ vs. $\quad \mathrm{SI} / \mathrm{R}+\mathrm{V} . \quad \mathrm{N}=14-16$ 
574 wells/group for superoxide production assay. N=8-10 wells/group for gp91 ${ }^{\text {phox }}$ 575 expression. Assays were performed 3 hours after reperfusion or sham reperfusion.

577 Figure 6. Effect of gAPN on SI/R-induced iNOS expression (A) and effect of 1400W, 578 a selective iNOS inhibitor on $\mathrm{SI} / \mathrm{R}$-induced peroxynitrite formation $(\mathrm{B}) .{ }^{*} * \mathrm{P}<0.01 \mathrm{vs}$. 579 sham $\mathrm{SI} / \mathrm{R} ;{ }^{\#} \mathrm{P}<0.01$ vs. SI/R+V. N=14-16 wells/group with cardiomyocytes isolated 580 from 6 to 8 mice for nitrotyrosine assay. N=8-10 wells/group for iNOS expression. 581 Assays were performed 3 hours after reperfusion or sham reperfusion.

582

583 Figure 7. Effect of gAPN and DPI (an NADPH oxidase inhibitor) or their 584 combination on SI/R-induced peroxynitrite formation (A) and caspase-3 activation 585 (B). $\mathrm{P}<0.05,{ }^{* *} \mathrm{P}<0.01$ vs. sham $\mathrm{SI} / \mathrm{R} ;{ }^{\#} \mathrm{P}<0.01$ vs. $\mathrm{SI} / \mathrm{R}+\mathrm{V}$. N=14-16 wells/group 586 with cardiomyocytes isolated from 6 to 8 mice. Assays were performed 3 hours after 587 reperfusion or sham reperfusion. 
A

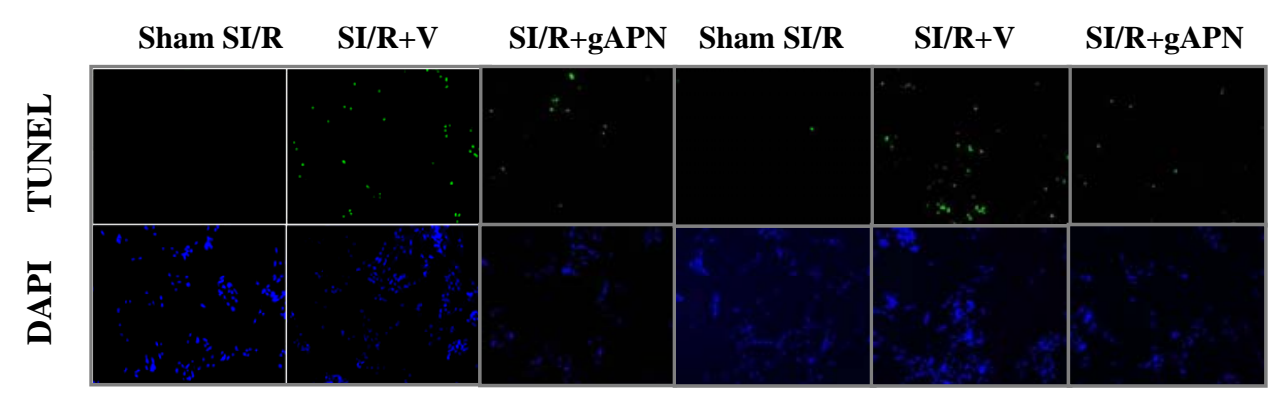

B

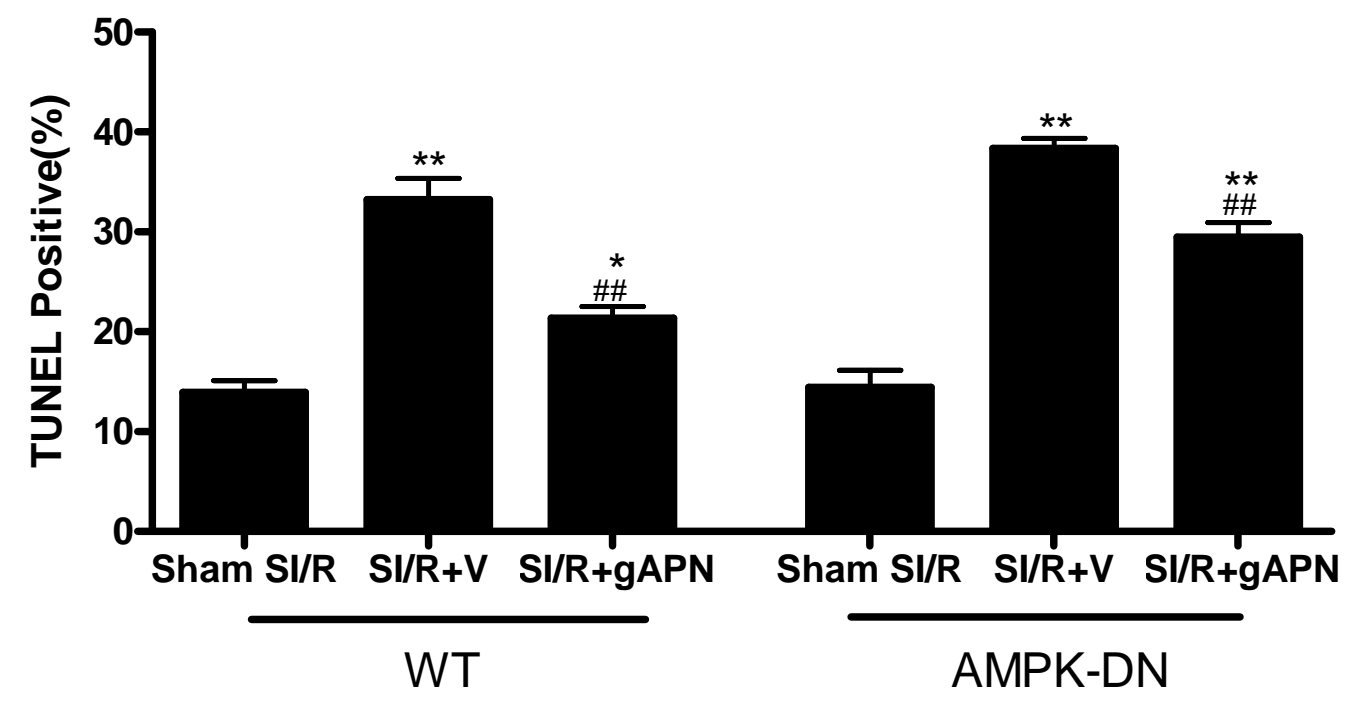

Figure 1 


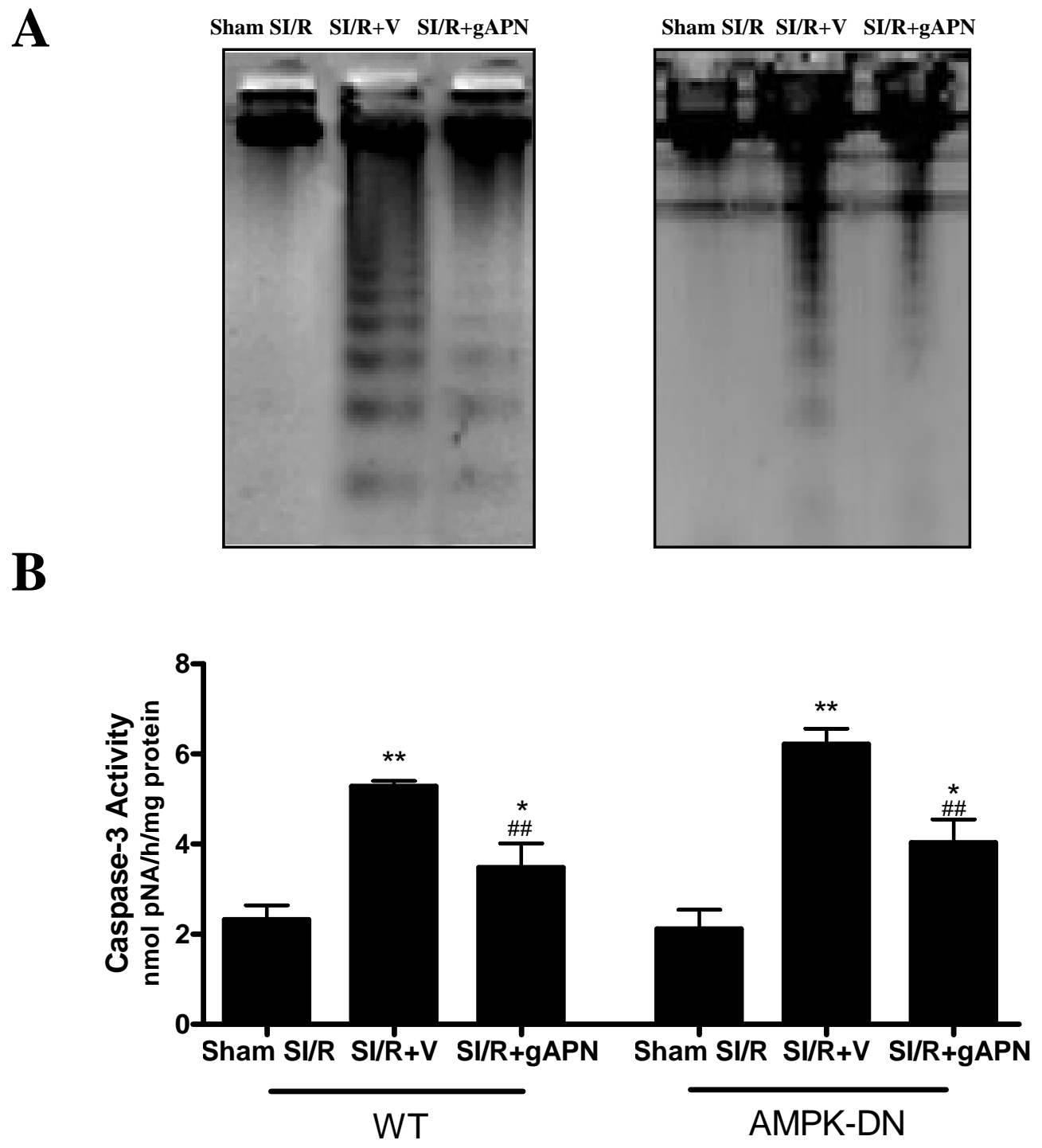

Figure 2 

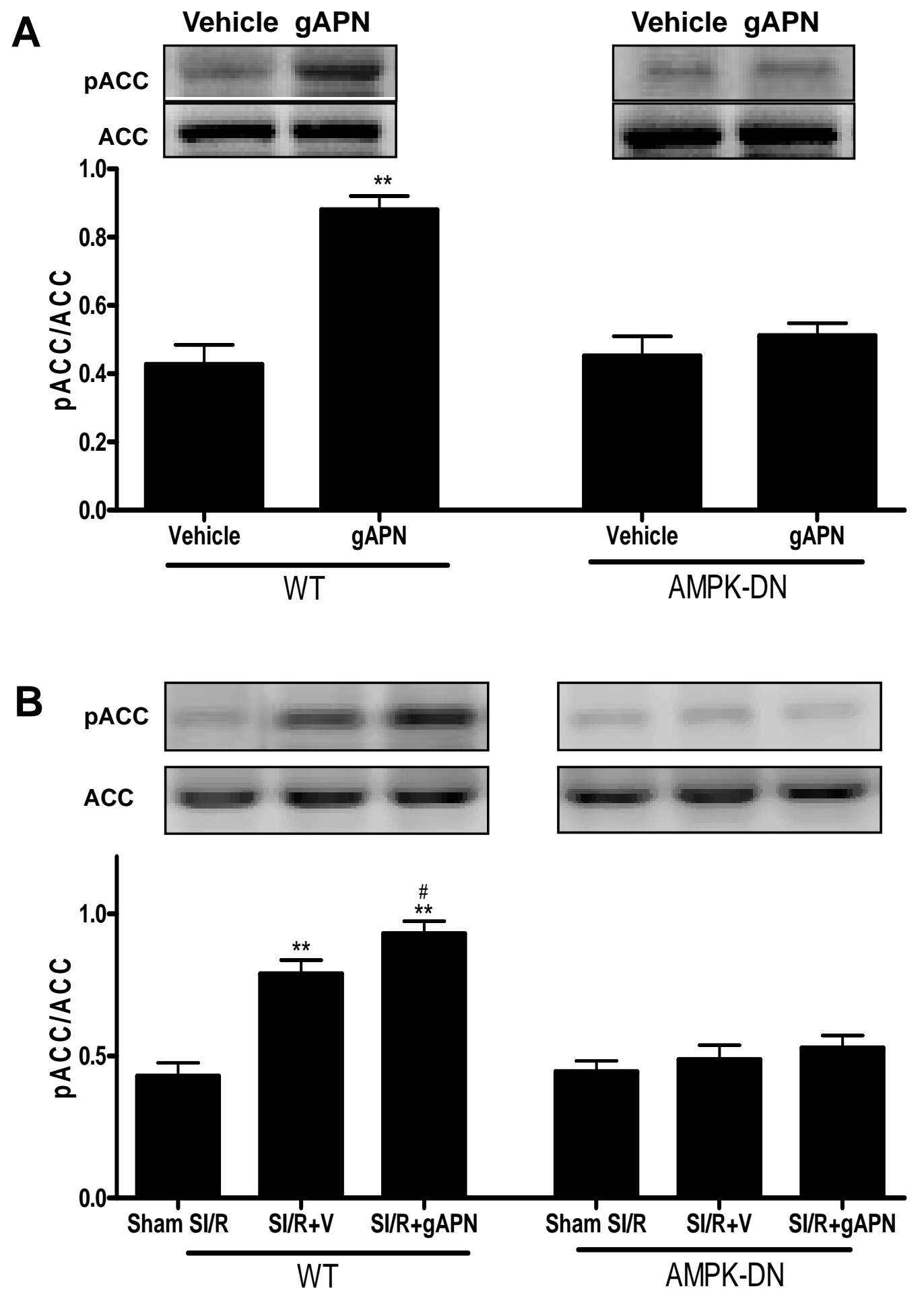

Figure 3 

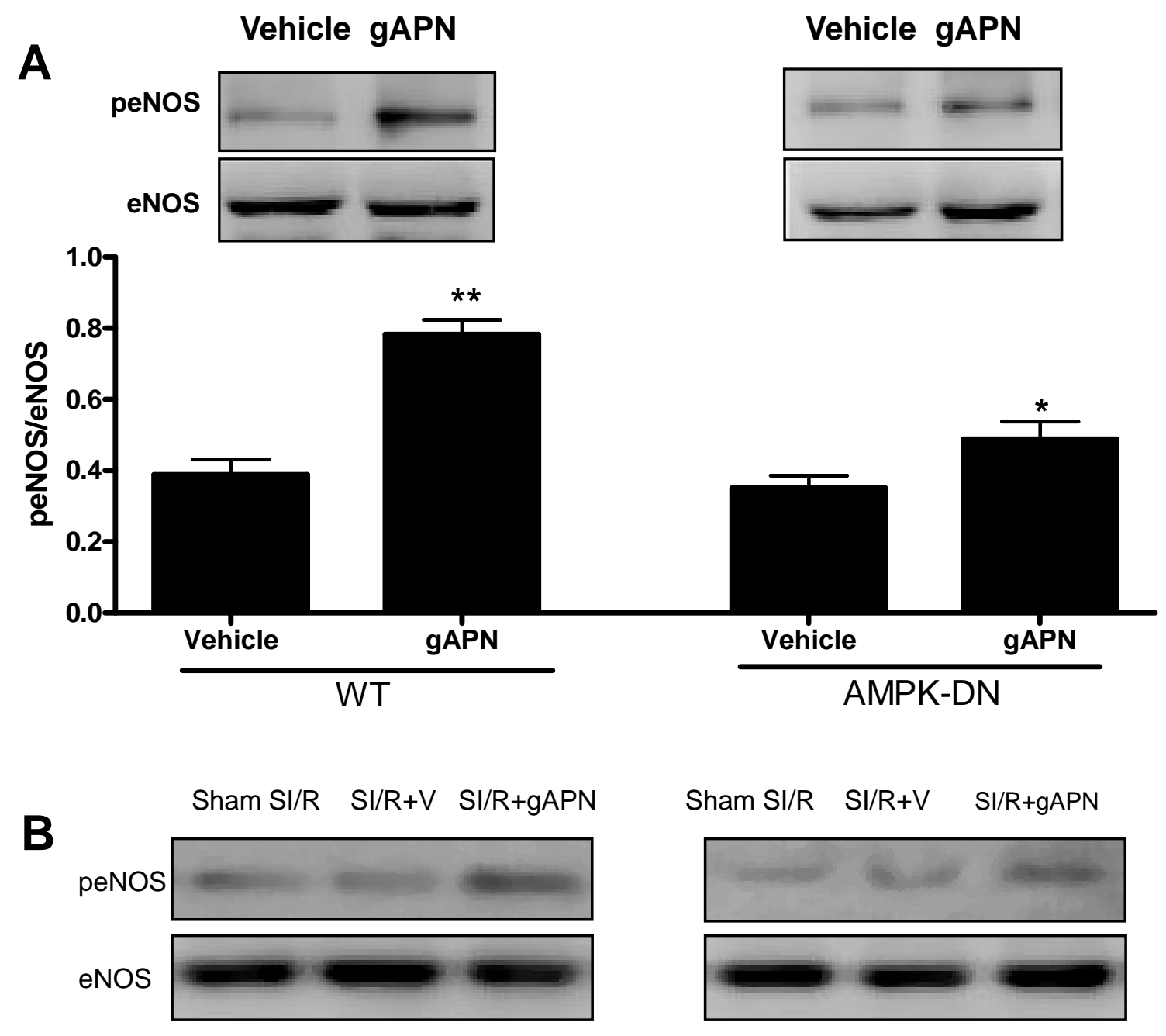

Sham SI/R SI/R+V SI/R+gAPN

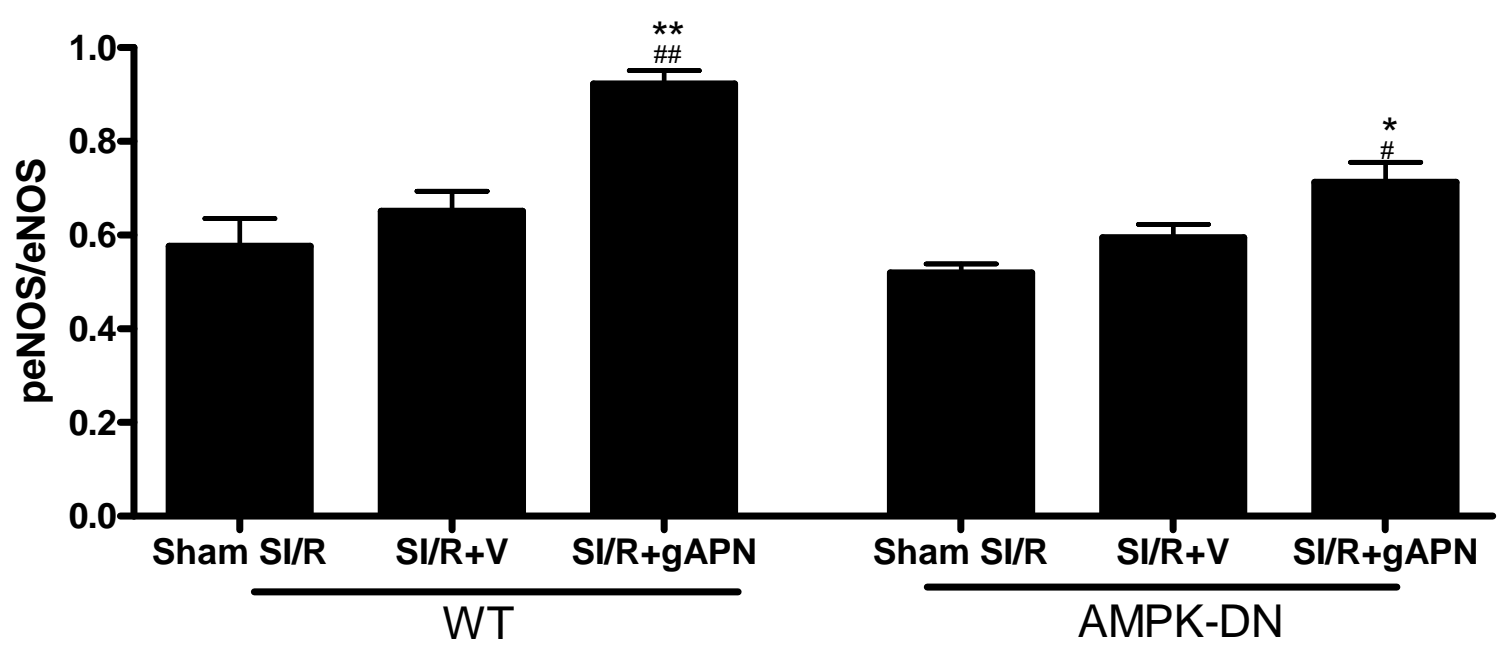

Figure 4 
A

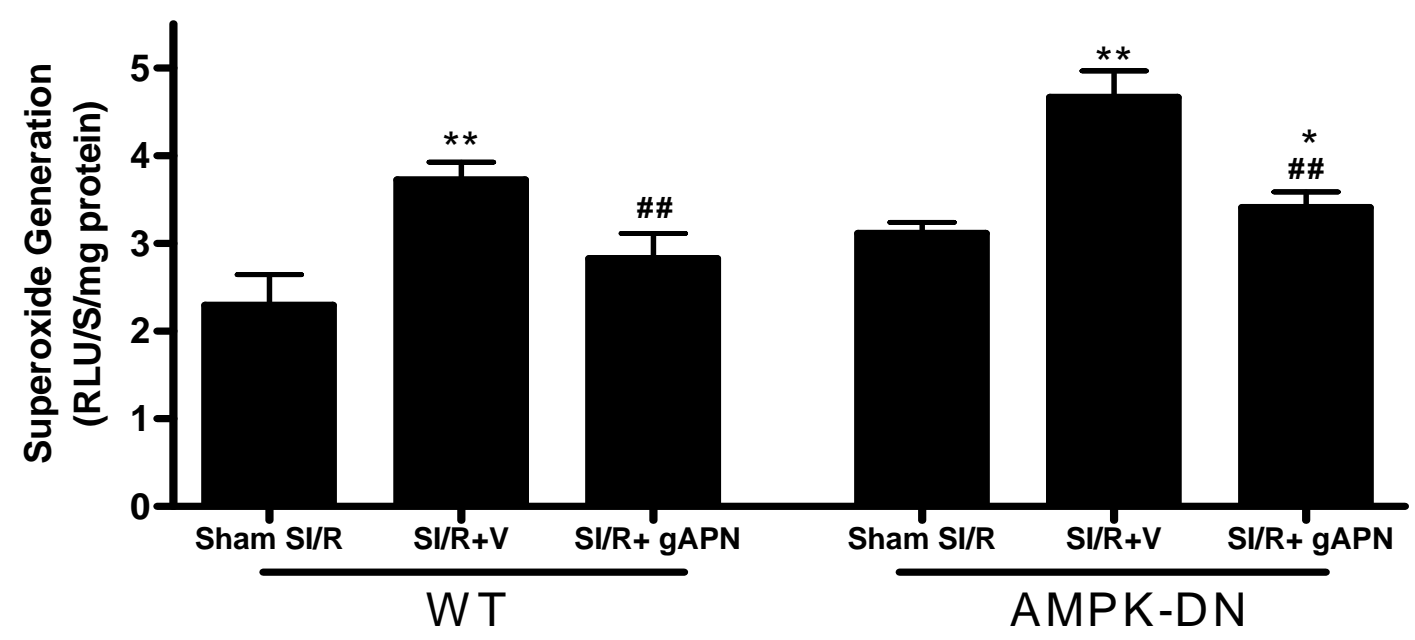

B

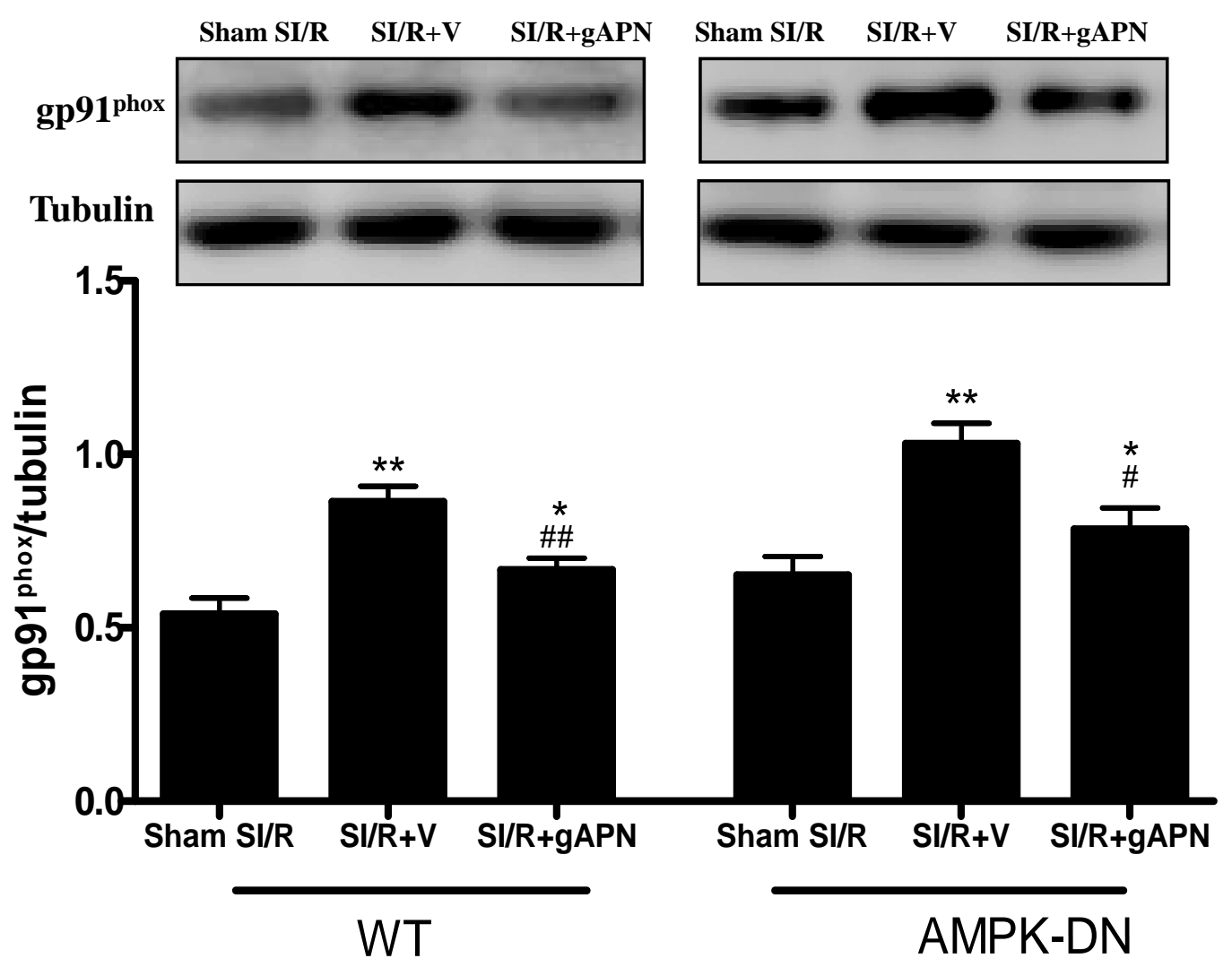

Figure 5 
A
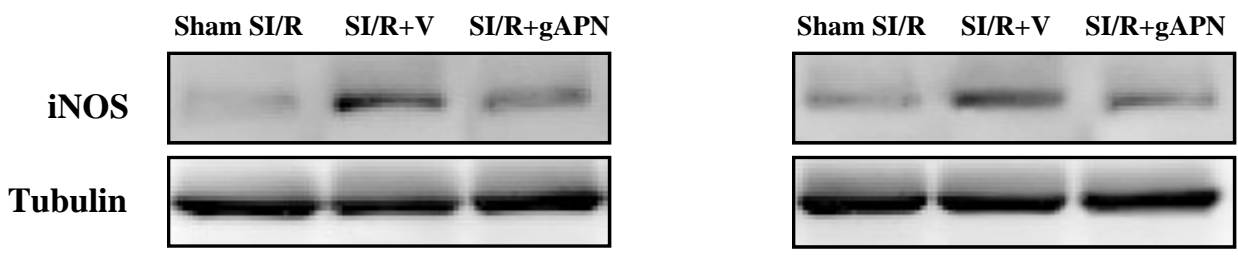

B

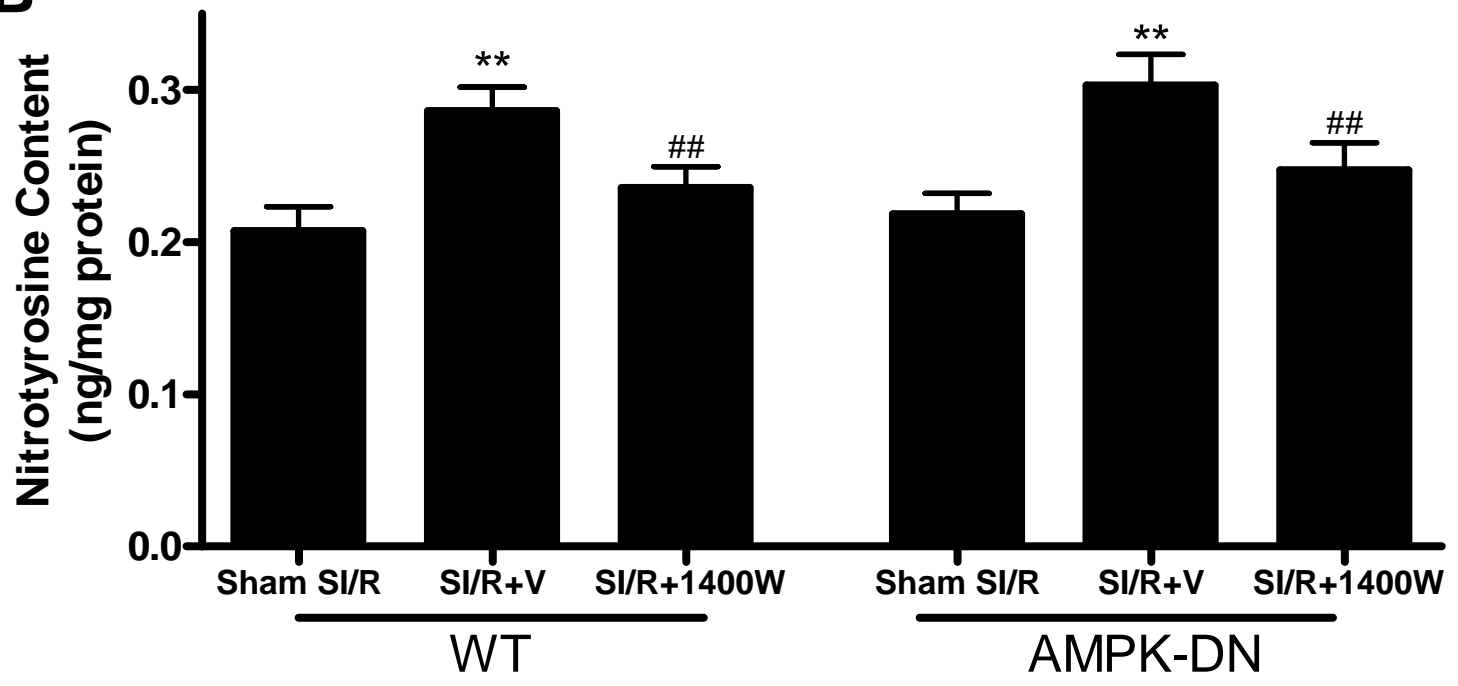

Figure 6 

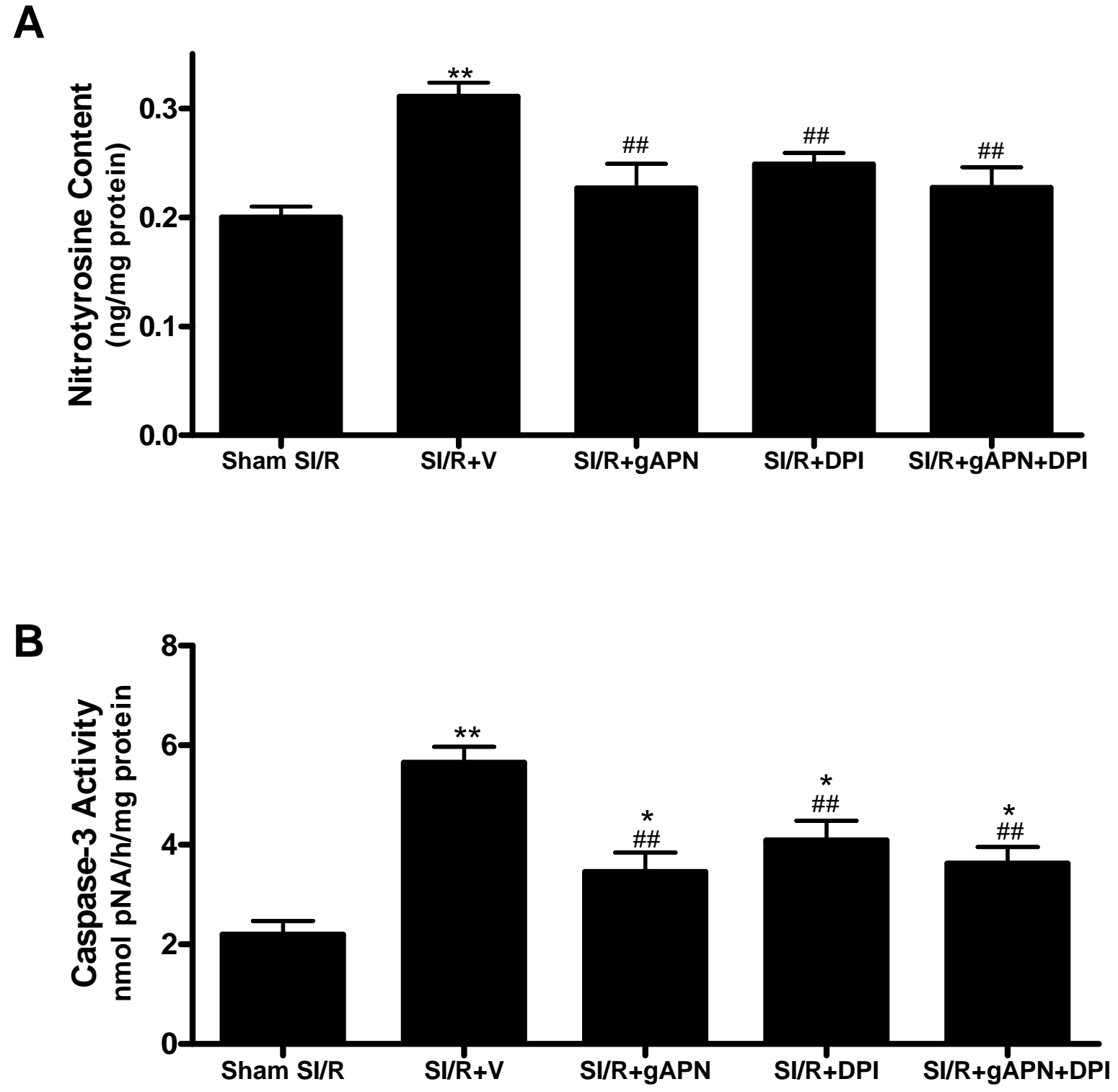

Figure 7 